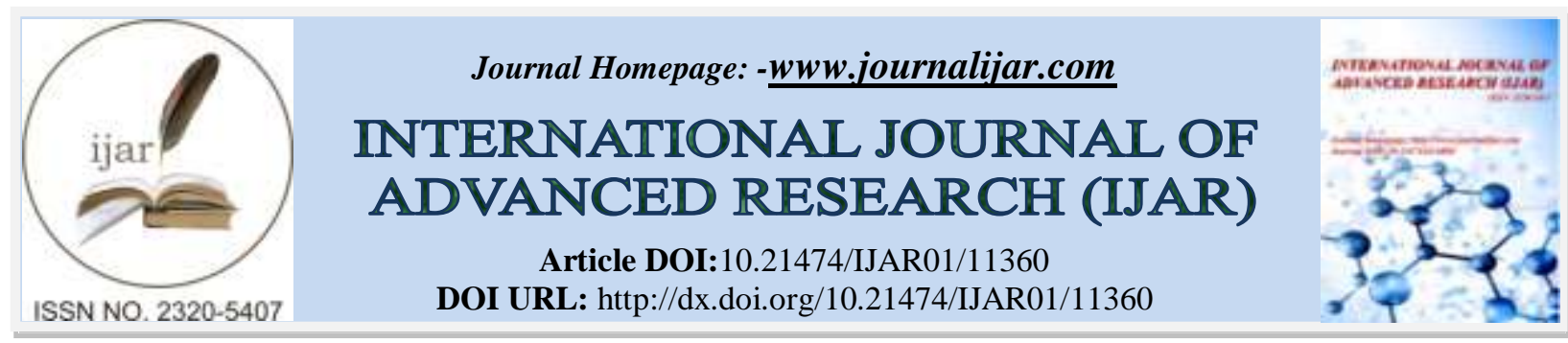

RESEARCH ARTICLE

\title{
SOCIAL AND CLINICAL FACTORS AFFECTING THE UREMIC CONDITION OF ANGOLAN PATIENTS WITH MALARIA
}

\author{
Santo Sebastião Doqui Zua ${ }^{1}$, Filomena Correia Filho Sacomboio ${ }^{2}$, Eduardo Ekundi Valentim ${ }^{3}$ and Euclides \\ Nenga Manuel Sacomboio ${ }^{1}$ \\ 1. Instituto Superior de Ciências de Saúde da Universidade Agostinho Neto, Luanda-Angola.. \\ 2. Instituto Superior para as Tecnologias da Informação e Comunicação, Luanda-Angola. \\ 3. Instituto Superior Politécnico de Malanje, Malanje-Angola.
}

\section{Manuscript Info}

Manuscript History

Received: 20 May 2020

Final Accepted: 24 June 2020

Published: July 2020

Key words:-

I. Social Condition II. Clinical Condition

III. Uremic Condition. IV. Malaria

\begin{abstract}
According to the National Malaria Control Program, from January to March of this year 2020, 2,065,673 cases and 2,548 deaths were recorded in Angola in 2019. To verify the uremic changes of patients with malaria according to their social and clinical conditions during a period of 5 days of hospitalization. The study was conducted as cross-sectional and quantitative approach. Of the 184 patients, men (68\%), where aged between 21 and 30 years old $(45 \%)$ and patients with altered uremia (68\%), of these about $48 \%$ with increased uremia and 52\% with hyper uremia, the general urea mean was $53.3 \mathrm{mg} / \mathrm{dL}$ and at the end of the study $49.5 \mathrm{mg} / \mathrm{dL}$, in the patients of Belas (62.0 to $52.0 \mathrm{mg} / \mathrm{dL}$ ) and Luanda $(59.1$ to $50.5 \mathrm{mg} / \mathrm{dL}$ ), people who had a job showed the urea $57.7 \mathrm{mg} / \mathrm{dL}$ to 48.7 $\mathrm{mg} / \mathrm{dL}$. Patients with hyper uremia were with high parasitemia $(60 \%)$, the highest mean of urea was observed among patients with high pasitemia $(58.5$ to $37.0 \mathrm{mg} / \mathrm{dL}$ ), patients with medium parasitemia (49.3 to 79.0 $\mathrm{mg} / \mathrm{dL}$ ), patients treated with Artemether presented mean urea (less than $50.0 \mathrm{mg} / \mathrm{dL}$ ) and Artesunate $(77.8$ to $70.4 \mathrm{mg} / \mathrm{dL}$ ), the patients who were discharged (51.7 to $44.8 \mathrm{mg} / \mathrm{dL}$ ), who remained hospitalized (51.5 to 49.1 $\mathrm{mg} / \mathrm{dL}$ ) and patients who died (73.6 to $74.1 \mathrm{mg} / \mathrm{dL}$ ). The social factors may caused changes in the uremic condition, however, clinical factors such as degree of parasitemia and pharmacological treatment directly affect the uremic condition of patients with malaria and that uremic condition can be a predictor of mortality.

Copy Right, IJAR, 2020,. All rights reserved.
\end{abstract}

\section{Introduction:-}

The World Health Organization has warned that the number of deaths from malaria in sub-Saharan Africa could double to 769,000, as efforts to combat the disease face interruptions by the coronavirus pandemic (WHO, 2020). According to the National Malaria Control Program, from January to March of this year 2020, 2,065,673 cases and 2,548 deaths were recorded in Angola, numbers that exceed those verified in more than 467 fatalities in concerning to the same period in 2019 , becoming a worrying fact in a period in which the entire health system is aimed at combating COVID-19 (Angola, 2020).

Corresponding Author:Euclides Nenga Manuel Sacomboio

Address:- Instituto Superior de Ciências de Saúde da Universidade Agostinho Neto, Luanda-Angola. 
Studies show that severe malaria is a multi - organ disease that is defined by the presence of one or more diverse syndromes, including coma, metabolic acidosis, hyperparasitemia, severe anemia, and renal failure and, among these symptoms, the severity of the coma, metabolic acidosis and renal failure are strong predictors of mortality (White et al.,2014). In vitro studies have shown that a striking feature of Plasmodium falciparum (Pf) infection in the blood stage in humans is the development of deep hypoargininemia, leading to impaired bioavailability of nitric oxide (NO), as measured by reactive hyperaemia (Yeo et al., 2014).

This fact is explained because the urea cycle mediates the removal of toxic ammonia and recycles citrulline back into arginine, and arginine is converted into protective nitric oxide (NO) by the enzyme nitric oxide syntheses (NOS) in cerebral malaria, but it can also be converted to ornithine by the enzyme arginase (Gramaglia et al., 2019).

The permeability of the red cell membrane of cells infected with malaria and have shown a decrease in the membrane surface area, cell volume, the osmotically active fraction of water and osmotic permeability to water, measured by interrupted flow spectroscopy, transport proteins in the parasite's plasma membrane seem to be very specific, these membrane proteins facilitate the capture of the main source of energy, glucose and precursors of biosynthesis, such as nucleosides for DNA/RNA or glycerol for glycerolipids, which seems to be vital for the release efficient use of waste molecules derived from energy metabolism, for example, lactic acid or protein breakdown, such as ammonia and urea (Meier, Erler and Beitz, 2018; ).

A study of Afrifa and co-workers in Ghana have shown an association between malaria and levels of urea and creatinine in pregnancy with special prominence among pregnant women infected with malaria in the third trimester of pregnancy (Afrifa et al., 2017). Other studies carried out in Angola by our research team at the Josina Machel hospital in 2016, found that patients with low and high parasitemia were those with the highest clinical history of malaria infection and treatment, as well as the highest mean values for urea and creatinine, were observed in patients with low, high and hyper parasitemia (Sacomboio et al., 2020; Calice-Silva et al., 2018).

Although the aforementioned studies, there's no previously studies developed in the world and in Angola in particular, which demonstrate what factors may be associated with uremic changes in patients with malaria, were found, the present study sought to verify the uremic changes of patients with malaria according to their social and clinical conditions during 5 days of hospitalization.

\section{Methodology:-}

The study was conducted as a cross-sectional study and a quantitative approach. The study was approved by the Human Research Ethics Committee of the Higher Institute of Health Sciences (Official Letter No. 755/GD/ISCISA/018) and authorized by the Clinician management of Hospital Josina Machel - Maria Pia in Luanda (Official Letter No. 260/DPC/HJM/2018). All patients who agreed to participate in the study had to sign the informed consent form after being informed about the nature and objectives of the study.

\section{Patient recruitment:}

The study population consisted of 246 of the 184 patients admitted and hospitalized for malaria to the Hospital Josina Machel - Maria Pia between January 2019 to January 2020, where a 99\% confidence index was maintained with a margin of error of around 5\% and only those patients who met the selection criteria and agreed to participate in the study were included in the study, additional information was collected through an open and closed question questionnaire for patients aged 16 to 50 and only patients who were hospitalized for more than 4 days were included in the study. All patients over the age of 55, with a history of hypertensive disease, diabetes, chronic kidney disease, cerebral malaria, or other chronic diseases that can affect the uremic condition of patients were excluded from the study to avoid confusing bias in the data analysis.

\section{Diagnosis of malaria:}

The diagnosis of malaria was performed by Josina Machel hospital professionals using rapid malaria antigen test (SD-Bioline Malaria AG Pf/PAN) and confirmed with the technique of direct visualization of the parasite by Giemsa-stained peripheral blood thickening (Aregawi, Li, and Miraglia, 2017). Patients who presented parasitemia less than or equal to $40 \mathrm{p} / \mathrm{mm}^{2}$ were classified as low parasitemia, patients who presented parasitemia between 41 to $800 \mathrm{p} / \mathrm{mm}^{2}$ were classified as moderate parasitemia and patients who presented parasitemia above $800 \mathrm{p} / \mathrm{mm}^{2} \mathrm{were}$ classified as high parasitemia (Sacomboio et al., 2020). 


\section{Diagnosis of the uremic condition:}

Blood samples were collected by venipuncture technique in the median cephalic vein, with syringes and needles of 3 to $5 \mathrm{ml}$ after fulfilling all the principles of asepsis, then placed in $5 \mathrm{ml}$ biochemistry tubes with separator gel, blood count tubes containing EDTA and then centrifuged to obtain the serum used to measure urea in an automated biochemistry device (of the vital scientific Flexor $\mathrm{E}_{180}$ and Flexor $\mathrm{E}_{450}$ type) that involves the spectrophotometric determination of colored compounds (chromophore) obtained by the reaction between the biological sample to be analyzed and the reagent (chromogenic), giving rise to a colored product, which is a very sensitive colorimetric method.

The results were analyzed according to the reference values, following the protocols of the hospital Josina MachelMaria Pia, (normal serum urea between 15 to $45 \mathrm{mg} / \mathrm{dL}$ ). For the clinical data presented in the results of this study, the variations of the uremic condition of the patients were obtained using two exams, one performed on the admission of the patient to the hospital unit after the diagnosis and hospitalization for malaria and the other on the 4th day of hospitalization of the patient, taking into account that treatment with anti-malarial drugs at hospital level can vary between 3 to 5 days.

Depending on the uremia values, patients were classified as patients with normal uremia when the urea values were between 15 to $50 \mathrm{mg} / \mathrm{dL}$, patients with increased uremia when the blood urea values were between 51 to $80 \mathrm{mg} / \mathrm{dL}$, and patient's hyper uremic when urea values were greater than $81 \mathrm{mg} / \mathrm{dL}$.

\section{Statistical analysis:}

All descriptive statistics information data and clinical outcome data were entered into an SPSS v20 database statistical program (IBM SPSS Statistics, USA) and analyzed for the presentation of study results and in tables, the graphs as prepared in the Sigmaplot 12 statistical program (Systat Software, Inc.).

\section{Results:-}

The general data of the study (table 1) show that of the 184 patients hospitalized with malaria and accompanied in the present study, women represented 77/184 (42\%) and men represented 107/184 (68\%), on hospital admission, $126 / 184(68 \%)$ of the patients had normal uremia, 58/184 (32\%) had uremia above the reference values, of this $28 / 58(48 \%)$ presented with increased uremia and 30/58 (52\%) were in the condition of hyper uremia, with an average of general urea in the population of $53.6 \mathrm{mg} / \mathrm{dL}$. These results underwent small changes after the 4 days of hospitalization, where it was noticed that the number of patients with normal uremia reached 132/184 (73\%), while the number of patients with uremic increase reduced to 52/184 (28\%), with no change in the number of patients with increased uremia, which continued to represent $28 / 52$ (54\%), but there was a reduction in the number of patients with hyper uremia, which went on to $24 / 52(46 \%)$ and the general mean of urea decreased to $49.5 \mathrm{mg} / \mathrm{dL}$.

When verifying if the uremic behavior was related to the age group (table 1), it was observed that the increased uremia was higher in patients aged 21 to 30 years, who represented 13/28 (46\%) at admission and 14/28 (50\%) at end of the study, patients aged 16 to 20 years who represented 9/28 (30\%) at admission and became 3/28 (11\%) at the end of the study and patients aged 31 to 40 years who at admission represented 6/28 (20\%) and became 10/28 (42\%) at the end of the study. Hyper uremia was mostly observed in patients aged 21 to 30 years who represented $15 / 30(50 \%)$ at admission and started to represent 10/24 (42\%) at the end of the study, patients aged 31 to 40 years at admission represented $9 / 30(30 \%)$ and now represent $6 / 24(25 \%)$ at the end of the study, patients under the age of 20 and over 40 years represented on admission 3/30(10\%) each and started to represent 5/24 (21\%) among those under 20 and 3/24 (13\%) among those over 40. The greatest variation in the mean urea was observed in patients aged 21 to 30 years whose mean urea was $59.3 \mathrm{mg} / \mathrm{dL}$ at admission and increased to $51.1 \mathrm{mg} / \mathrm{dL}$ at the end of the study. In all other groups, although there were some variations in the number of patients with normal uremia, the mean urea on admission did not vary much from the average urea after 4 days of hospitalization, however, patients under 20 and over 40 years, were the ones with average normal uremia at admission and the end of the study (less than $50 \mathrm{mg} / \mathrm{dL}$ ).

Table 1:- Age groups of patients and uremic condition of patients with malaria.

\begin{tabular}{|c|c|c|c|c|c|c|c|c|c|c|}
\hline \multirow{2}{*}{$\begin{array}{l}\text { Age } \\
\text { groups }\end{array}$} & \multicolumn{3}{|c|}{ Initial Uremia (admission) } & \multirow{2}{*}{ Urea } & \multicolumn{3}{|c|}{ Final Uremia (4 days later) } & \multirow{2}{*}{ Ul } & \multirow{2}{*}{$\begin{array}{l}\text { Sub } \\
\text { tota }\end{array}$} & \multirow{2}{*}{$\begin{array}{c}\text { Genre } \\
\text { Female/Male }\end{array}$} \\
\hline & Normo & Incresed & Hyper & & Normo & Incresed & Hyper & & & \\
\hline
\end{tabular}




\begin{tabular}{|c|c|c|c|c|c|c|c|c|c|c|c|}
\hline \multirow[t]{2}{*}{$\begin{array}{l}\text { Urea } \\
\text { bands }\end{array}$} & $\begin{array}{c}15-50 \\
\mathrm{mg} / \mathrm{dL}\end{array}$ & $\begin{array}{c}51-80 \\
\mathrm{mg} / \mathrm{dL}\end{array}$ & $\begin{array}{c}\geq 81 \\
\mathrm{mg} / \mathrm{dL}\end{array}$ & $\mathrm{mg} / \mathrm{dL}$ & $\begin{array}{c}15-50 \\
\mathrm{mg} / \mathrm{dL}\end{array}$ & $\begin{array}{c}51-80 \\
\mathrm{mg} / \mathrm{dL}\end{array}$ & $\begin{array}{c}\geq 81 \\
\mathrm{mg} / \mathrm{dL}\end{array}$ & $\mathrm{mg} / \mathrm{dL}$ & & $\mathbf{F}$ & M \\
\hline & $\mathrm{n}$ & $\mathrm{n}$ & $\mathrm{n}$ & Mean & $\mathrm{n}$ & $\mathrm{n}$ & $\mathrm{n}$ & Mean & $\mathrm{n}$ & $\mathrm{n}$ & $\mathrm{n}$ \\
\hline Less 20 & 24 & 9 & 3 & 46,9 & 28 & 3 & 5 & 45,9 & 36 & 14 & 22 \\
\hline $21-30$ & 54 & 13 & 15 & 59,3 & 58 & 14 & 10 & 51,1 & 82 & 36 & 46 \\
\hline $31-40$ & 29 & 6 & 9 & 53,1 & 28 & 10 & 6 & 53,3 & 44 & 18 & 26 \\
\hline $\begin{array}{l}\text { Above } \\
40\end{array}$ & 19 & 0 & 3 & 41,4 & 18 & 1 & 3 & 41,7 & 22 & 9 & 13 \\
\hline Total & 126 & 28 & 30 & 53,3 & 132 & 28 & 24 & 49,5 & 184 & 77 & 107 \\
\hline
\end{tabular}

(Normo)- patients who presented normouremic with urea values between 14 to $50 \mathrm{mg} / \mathrm{dL}$. (Incresed) - patients who presented with increased uremia and urea values were between 51 to $80 \mathrm{mg} / \mathrm{dL}$.. (Hyper) - patients who presented hyper uremia with urea values greater than $81 \mathrm{mg} / \mathrm{dL}$.

It was noticed in the study, that the majority of the population that participated in the study (Fig.1) have come from the municipality of Luanda representing 67/184 (36\%), followed by patients from the municipality of Cazenga representing 56/184 (30\%) and patients from Viana and Cacuaco who represented 33/184 (18\%) and 14/184 (8\%) of the studied patients, respectively. Increased uremia was seen mostly in Luanda patients who represented 12/28 (43\%) at admission and the end of the study they became 14/28 (50\%), a patient from Cacuaco and Viana who contributed to admission with 5/28 (18\%) each, after 4 days of hospitalization, now represent 3/28 (13\%) each. When assessing hyper uremia according to the place of residence, the majority of patients in this condition were also found to be from the municipality of Luanda, who represented 11/30 (37\%) at admission and started to represent $10 / 24(42 \%)$ at the end of the period study, patients from the municipality of Cazenga represented 6/30 (20\%) at admission and at the end of the study they started to represent 5/24 (21\%) and patients from the municipality of Viana who represented 5/30 (17\%) and at the end of the study, it started to represent 3/24 (13\%). When assessing hyper uremia according to the place of residence, the majority of patients in this condition were also found to be from the municipality of Luanda, who represented 11/30 (37\%) at admission and started to represent 10/24 (42\%) at the end of the period. Patients from the municipality of Cazenga represented 6/30 (20\%) at admission and at the end of the study they started to represent 5/24 (21\%) and those who came from the municipality of Viana represented $5 / 30(17 \%)$ and at the end of the study, it started to represent $3 / 24(13 \%)$.

Except for the patients from Viana and Cazenga (Fig.1), it was found that all other groups have had increased mean values of urea at entry, with the highest mean value of urea observed among Kilamba Kiaxi patients having a mean of urea of $66.6 \mathrm{mg} / \mathrm{dL}$ at admission and $67.7 \mathrm{mg} / \mathrm{dL}$ at the end of the study, among the patients who had a significant reduction in mean urea at admission and end of the study, were patients from the municipality of Belas (from 62 $\mathrm{mg} / \mathrm{dL}$ to $52 \mathrm{mg} / \mathrm{dL}$ ), Luanda (from $59.1 \mathrm{mg} / \mathrm{dL}$ to $50.2 \mathrm{mg} / \mathrm{dL}$ ) and among patients from other regions that do not belong to the province of Luanda, where the mean value of urea was found from $54 \mathrm{mg} / \mathrm{dL}$ at admission to 45.6 $\mathrm{mg} / \mathrm{dL}$ at the end of the study, while the other groups remained with the urea average very close at admission and the end of follow-up. 


\section{Parasitic condition/Uremic Condition}

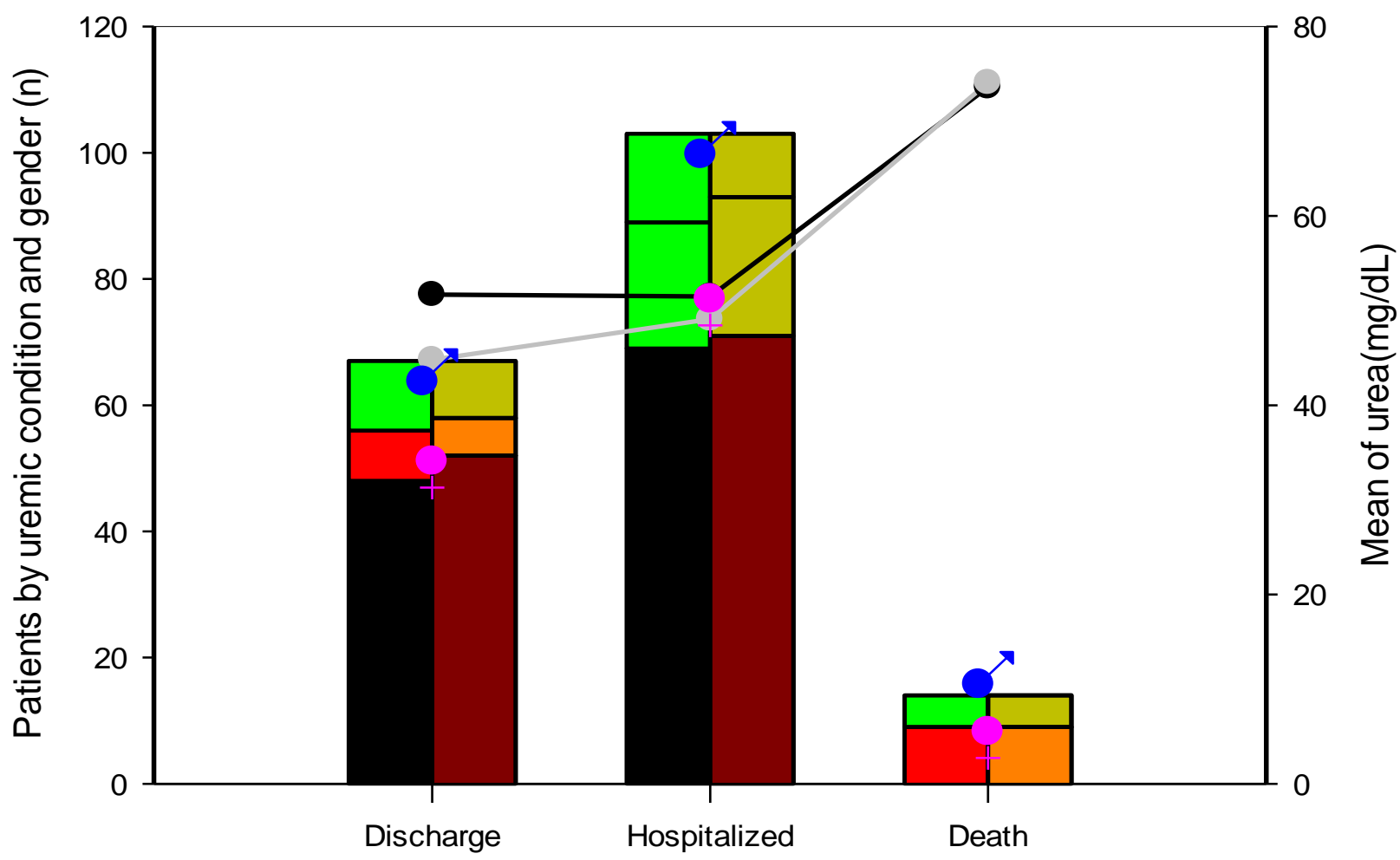

\begin{tabular}{|l|}
\hline Normouremic(I) \\
Increased uremia(I) \\
$\square$ Hyper uremia(I) \\
Normouremic(F) \\
$\square$ Increased uremia(F) \\
$\square$ Hyper uremia(F) \\
- Mean of urea(I) \\
- Mean of urea(F) \\
$+\quad$ Female \\
Male
\end{tabular}

Hospital outcome

Fig 1. Place of residece and uremic condition. The data presented in the graph were described according to the reference of the patients according to the locality in which they lived, which may be neighborhoods, towns and communes and others that were later organized according to the municipalities of Luanda province (Belas, Cacuaco, Cazenga, Kilamba Kiaxi, Luanda and Viana), which is the capital of the country and other provinces of Angola (Others). (Normouremic): patients who had normal uremia at admission (Initial-I) and at the end of the study (Final-

F). (Increased uremia): patients who presented with increased uremia at admission (Initial-I) and at the end of the study (Final-F). (Hyper Uremia): patients who presented with hyper uremia at admission (Initial-I) and at the end of the study (Final-F).

Figure 1:- Place of residence and uremic condition.

When assessing whether there is a relationship between the profession and the uremic condition (Fig.2), it was observed that the majority of patients hospitalized for malaria were unemployed people 64/184 (35\%), followed by students 49/184 (27\%) and self-employed patients 41/184 (22\%). It was found that patients with increased uremia were mostly students who represented 12/28 (42\%) on admission that after 4 days of hospitalization became $9 / 28$ (32\%), the unemployed represented 9/28 (32\%) in the admission and started to represent 8/28 (29\%) at the end of 
the study, patients who worked in companies represented 4/28 (14\%) at admission and the end of the study started to represent 7/2 (25\%). Patients with hyper uremia were mostly unemployed who represented 11/28 (39\%) on admission and at the end of the study, they represented 9/24 (38\%), followed by patients who worked in companies represented $7 / 28(23 \%)$ and at the end of the study they now represent $4 / 24$ (14\%), self-employed patients and student who represented 6/30 (20\%) each on admission, there was no variation for self-employed patients who started to represent 6/24 (25\%) and students who started to represent 5/24 (21\%) of individuals with hyper uremia at the end of the study.

The mean values of urea that suffered the most variation were among those who worked in a company, which went from $57.7 \mathrm{mg} / \mathrm{dL}$ on admission to $48.7 \mathrm{mg} / \mathrm{dL} 4$ days after admission, the only group that presented normal uremia at the entrance and at the end of the study were self-employed patients whose mean urea above $50 \mathrm{mg} / \mathrm{dL}$, all other groups had mean urea above $50 \mathrm{mg} / \mathrm{dL}$ and remained unchanged until the end of the study (Fig .2).

\section{Occupation/Uremic Condition}

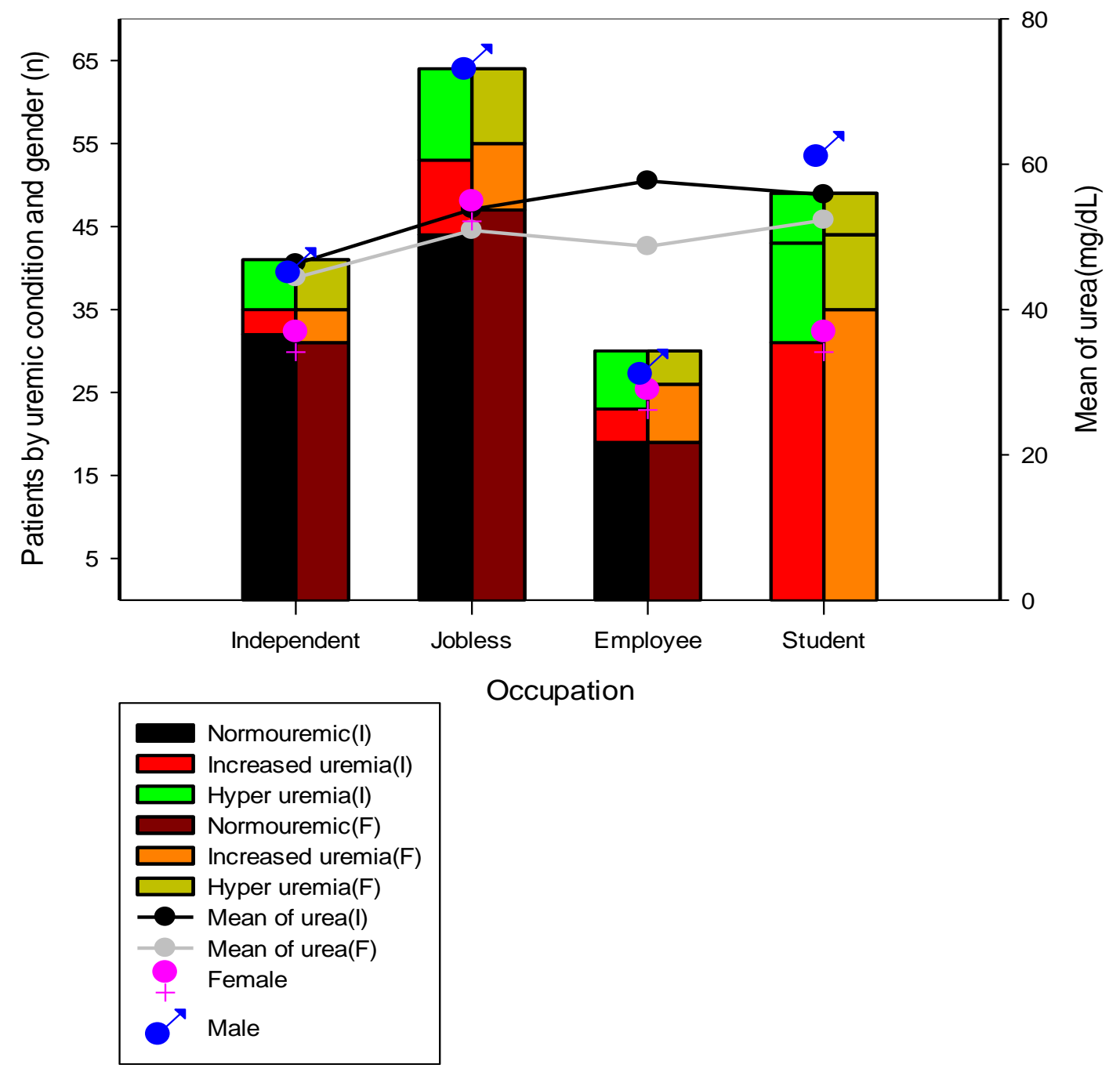

Fig 2. Occupation and uremic condition. (Independent): patients who are self-employed, providing services to individual or legal persons on a temporary basis. (Jobless): patients who stated that they did not perform any remunerative activity and were unemployed. (Employee): patients who work in public or private companies and who have an employment contract for an indefinite period. (Student): patients who said they were just students and did not perform any other remunerative activity.

Figure 2:- Occupation and uremic condition. 
When assessing whether the parasitemia affected the patient's uremic condition (Fig.3), it was found that on admission, most of the studied patients had high parasitemia, representing about 75/184 (41\%), patients with moderate parasitemia represented 37/184 (20\%) and patients with low parasitemia represented $72 / 184(39 \%)$. During this period, most patients with increased uremia were mostly patients with high parasitemia 16/28 (57\%), patients with moderate parasitemia represented 7/28 (25\%) and low parasitemia patients represented 5/28 (18\%). Hyper uremia was greater in patients with high parasitemia 18/30 (60\%), patients with low parasitemia represented $8 / 30(27 \%)$ and with moderate parasitemia represented 4/30 (13\%). After 4 days of hospitalization, it was noticed that most patients already had low parasitemia 178/184 (97\%) and it was only in this group where all patients with increased uremia were found (28/28) and all patients with hyper uremia (24/24). In patients with high parasitemia, there was a reduction of 75 patients with mean urea of $58.5 \mathrm{mg} / \mathrm{dL}$ at admission to 1 patient with mean urea of $32 \mathrm{mg} / \mathrm{dL}, 4$ days after admission. Although the number of patients with moderate parasitemia decreased from 37 patients on admission to 5 patients at the end of the study, the urea average increased from $59.3 \mathrm{mg} / \mathrm{dL}$ to 79.0 $\mathrm{mg} / \mathrm{dL}$. There were 72 patients with low parasitemia at admission, with a mean urea of $49.7 \mathrm{mg} / \mathrm{dL}$ and at the end of the study; it became 178 with mean urea of $48.7 \mathrm{mg} / \mathrm{dL}$.

\section{Parasitic condition/Uremic Condition}
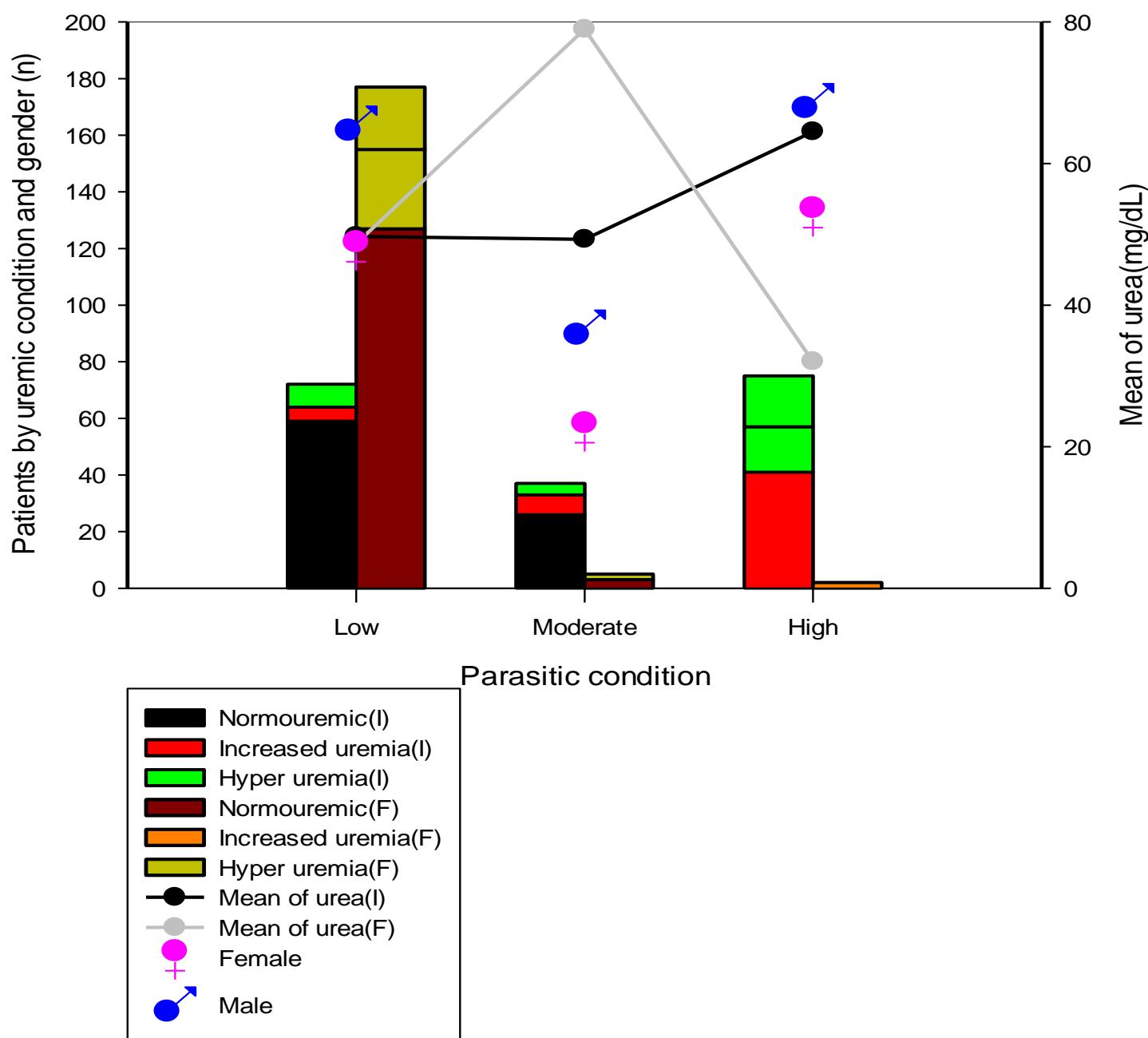

Parasitic condition

Fig 3. Parasitemia and uremic condition. (Low parasitemia): patients who, on admission or 4 days after admission, had parasitemia below 41 plasmodium $/ \mathrm{mm}^{2}$. (Moderate parasitemia): patients who, on admission or 4 days after admission, had parasitemia between 41 to 800 plasmodium $/ \mathrm{mm}^{2}$. (High parasitemia): patients who, on admission or 4 days after admission, had parasitemia greater than 800 plasmodium/mm ${ }^{2}$.

Figure 3:- Parasitemia and uremic condition.

It was found that on admission, most of the patients studied were treated with Artemether (Fig.4), representing about 152/184 (83\%), patients treated with Artesunate represented 12/184 (15\%) and patients treated with Quinine 
represented only 4/184 (2\%). During this period, most patients with increased uremia were patients treated with Artemether who represented 22/28 on admission (79\%), while those treated with Artesunate represented 6/28 (21\%) on admission, these results did not undergo significant changes at the end of the study. Patients with hyper uremia were mostly treated with Artemether 18/30 (60\%) and Artesunate, which represented 12/30 (40\%) at admission, at the end of the study, patients in this condition treated with Artemether became 12/24 (50\%), with Artesunate represented 10/24 (42\%) and treated with Quinine now represent 2/24 (8\%). Artemether-treated patients had normal urea averages at admission and the end of the study (less than $50 \mathrm{mg} / \mathrm{dL}$ ), Artesunate-treated patients maintained high urea averages from admission to the end of the study $(77.8 \mathrm{mg} / \mathrm{dL}$ and $70.4 \mathrm{mg} / \mathrm{dL}$, respectively), while patients treated with Quinine initially had urea of $14 \mathrm{mg} / \mathrm{dL}$ at admission and this value increased to $71 \mathrm{mg} / \mathrm{dL}$ at the end of the study.

\section{Parasitic condition/Uremic Condition}
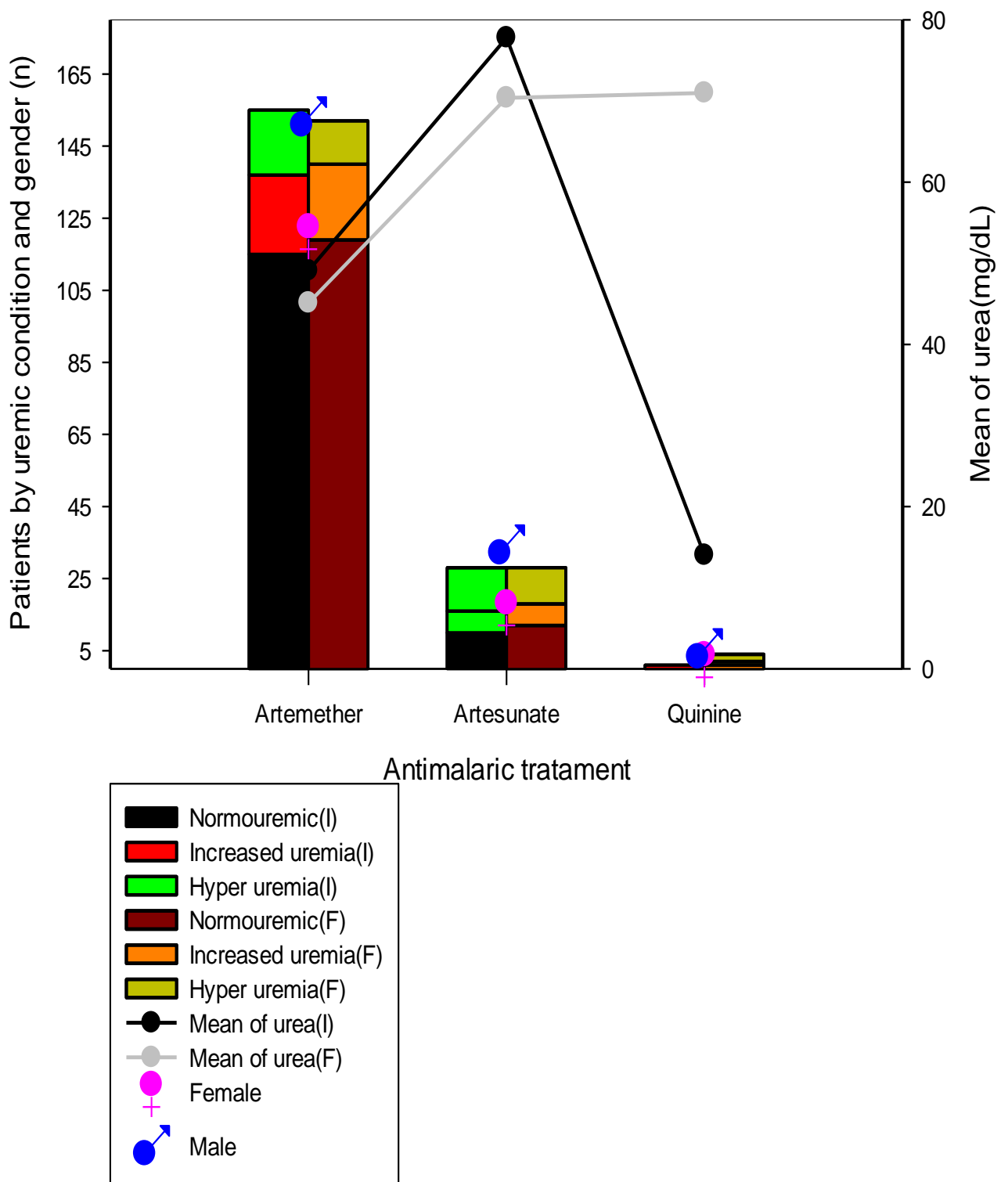

Fig 4. Antimalarial tratament and uremic condition. (Artemether): patients who were hospitalized for more than 4 days and underwent antimalarial treatment solely and exclusively with artemether. (Artesunate): patients who were hospitalized for more than 4 days and underwent antimalarial treatment solely and exclusively with artemether. (Artemether): patients who were hospitalized for more than 4 days and underwent anti-malarial treatment solely and exclusively with artemether.

Figure 4:- Antimalarial tratament and uremic condition. 
When we verified how the uremic condition was associated with the outcomes (Fig.5), we noticed that the mortality among patients with malaria was $15 / 184(8 \%)$, and hospital discharge represented $63 / 184(36 \%)$ of the patients, the majority of patients $103 / 184(56 \%)$ after the end of the follow-up (maximum of 5 days) remained in the hospital. The increased uremia showed a significant reduction among patients who were discharged from the hospital, and upon admission, these patients represented 8/28 (29\%) and at the end of the study, they represented 6/28 (21\%), among hospitalized patients there was a slight increase in the number of patients with increased uremia, which represented 20/28 (71\%) at admission and at the end of the study, they represented 22/28 (79\%), and no patient who died was in the condition of a patient with increased uremia. Patients with hyper uremia were mostly patients who remained hospitalized, representing 14/30 (47\%) on admission and 10/24 (41\%) at the end of the study, followed by patients who were discharged from hospital who represented 11/30 (37\%) on admission and at the end of the study they represented 9/24 (38\%), patients who died represented 5/30 (16\%) on admission and this number remained at the end of the study $5 / 24(21 \%)$. It was also found that the mean urea of patients who were discharged and who remained hospitalized was slightly high (just above $50 \mathrm{mg} / \mathrm{dL}$ ) at admission and decreased to values considered normal (below $50 \mathrm{mg} / \mathrm{dL}$ ) at the end of the study, however, patients who died on admission had a mean urea of 73.6 $\mathrm{mg} / \mathrm{dL}$ of urea and at the end of the study the mean urea was $74.1 \mathrm{mg} / \mathrm{dL}$.

\section{Parasitic condition/Uremic Condition}

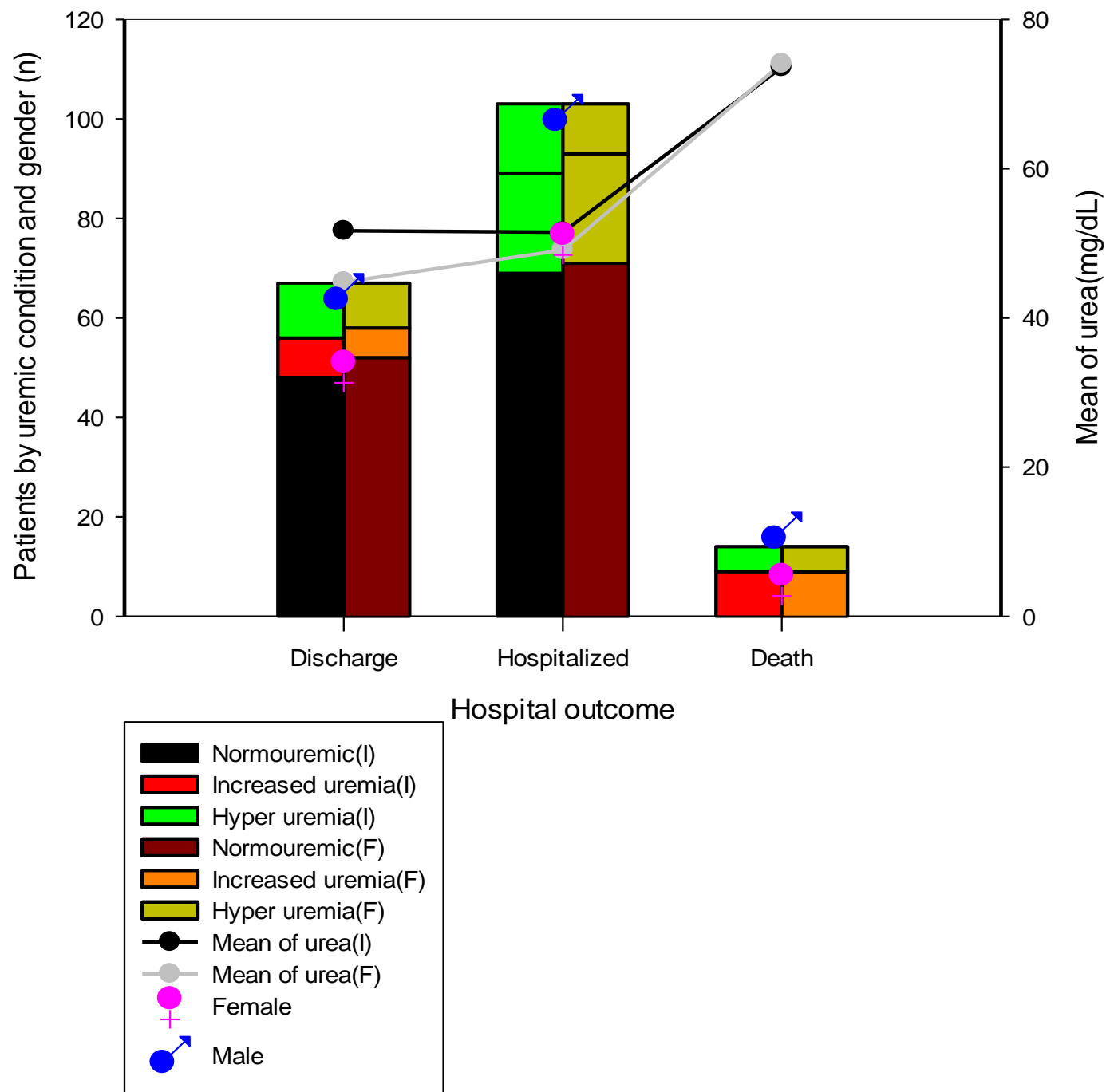

Fig 5. Outcome and uremic Condition. (Discharge): patients who, after the days of follow-up, were discharged for improving their clinical condition after malaria infection. (Hospitalized): patients who, after the days of follow-up, remained hospitalized because they still did not show improvement in their clinical condition after malaria infection. (Death): patients who died during the follow-up period.

Figure 5:- Outcome and uremic condition. 


\section{Discussion:-}

Malaria falciparum is a high prevalence disease in Angola and most tropical countries, and it's associated with a high rate of mortality. The data show that men were the majority of the population with malaria (68\%), and most of them were aged between 21 and 30 years old (45\%) and patients with altered uremia at admission represented around $68 \%$, of these about $48 \%$ presented with increased uremia and $52 \%$ with hyper uremia. The general urea average at admission was $53.3 \mathrm{mg} / \mathrm{dL}$ and at the end of the study, it decreased to $49.5 \mathrm{mg} / \mathrm{dL}$ (Table 1). A previous study carried out in the same hospital, showed that of the 135 patients were admitted to the hospital with malaria and $86(63.7 \%)$ were included in the study, the mean age was $21.5( \pm 9.4)$ years, 61/86 (71\%) were male and the blood urea nitrogen of the group with increased urea on admission (day 1) was $99.4 \pm 61.9 \mathrm{mg} / \mathrm{dL}$, respectively (Sacomboio et al., 2020). Since most patients with severe malaria were children or young adults with normal premorbid renal function, a plasma creatinine above $3 \mathrm{mg} / \mathrm{dL}$ is used as a criterion for severe malaria, this plasma creatinine level roughly corresponds to a blood urea $57 \mathrm{mg} / \mathrm{dL}$ or blood urea of $122 \mathrm{mg} / \mathrm{dL}$, although patients with severe malaria may be hypercatabolic and dehydrated, which increases the urea/creatinine ratio (WHO, 2014). It has been reported that malaria is one of the factors responsible for acute renal failure in children in malaria-endemic areas and this adverse effect of the malaria parasite on the kidney can lead to an increase in blood urea, hypernatremia, hyperkalemia, the low specific urine severity, metabolic acidosis and low ratio of urea in urine and blood (Padhi and Mishra, 2012).

Variation in the number of patients with altered uremia was noticed in relation to the place of residence, and it was almost insignificant between the admission period and until the end of the study, since except in the municipality of Viana, where 2 patients had reversed hyper uremia to normal and the municipality of Luanda where 2 patients left the situation of increased uremia to normal. Patients from all other municipalities did not show significant changes in their uremic condition, since in some cases this change happened in only 1 patient, although it was observed that the greatest variation in mean urea occurred in the patients from the municipality of Belas $(62 \mathrm{mg} / \mathrm{dL}$ to $52 \mathrm{mg} / \mathrm{dL})$, Luanda $(59.1 \mathrm{mg} / \mathrm{dL}$ to $50.5 \mathrm{mg} / \mathrm{dL})$ and in patients from other municipalities ( $54 \mathrm{mg} / \mathrm{dL}$ to $45.9 \mathrm{mg} / \mathrm{dL}) \mathrm{who}$ do not belong to the province of Luanda (Fig.1). This result seemed to be associated with the quality of life in these municipalities, as Belas and Luanda are municipalities in the central regions of Luanda, where the population's economic condition is mostly better than that of other municipalities. These data do not differ from a study conducted in the USA, where the authors showed that the permeability of the erythrocyte membrane to water was also affected by the intra-erythrocytic growth of the malaria parasite (Plasmodium falciparum), but there was no permeability of the urea that appeared to remain unchanged (Zanner et al., 2019).

When relating the uremic condition of the patients to the work condition, among the unemployed patients, 2 presented a change in the uremic condition from hyper uremia to normal, among workers employed in companies, this change happened in 3 patients who changed from hyper uremia to increased uremia. Among the patients who had increased uremia, the greatest change was observed among students where 3 of them left the condition of increased uremia to normal uremia, in all other cases this variation was only 1 patient who evolved to improve or worsen the uremic picture, however, only people who had a steady job showed a significant change in the average urea that went from $57.7 \mathrm{mg} / \mathrm{dL}$ to $48.7 \mathrm{mg} / \mathrm{dL}$ (Fig.2). Despite the reduced number of patients, these results are perhaps another sign that people with greater purchasing power improve the uremic condition because certainly as in hospitals in Angola food from home is allowed, their conditions for acquiring more nutritional foods may favor these changes. These results may help explain the fact that a study carried out on African children, which showed that plasma samples of urea and creatinine can be elevated on admission, especially in the presence of dehydration; values that return to normal during treatment, or that represent an independent risk factor for results in ruins, although acute kidney injury (AKI) is rare in children(Von Seidlein et al., 2012). A study with similar results, although it was carried out in children, carried out in Nigeria, showed a significant increase in urea in children with severe malaria infection, when compared to the group that had mild malaria infection and the control group, which suggests the severity of malaria infection has a great influence on the level of urea in the body of the infected person (Akanbi, 2015) and another study carried out in Sudan, stated that the increase observed in urea in the group of patients with severe malaria may be a result of the parasite's kidnapping in the renal microvasculature bed, the that can lead to ischemia (Zaki, Abdalla and Hayder, 2013).

It was noticed that the parasitemia affected the uremic condition, since, on admission, most patients with hyper uremia were patients with high parasitemia representing about $60 \%$ of the patients in this condition, although the number of patients with hyper uremia has reduced only from 30 to 24, it was noticed that the majority of patients who evolved from hyper uremia to normal uremia were patients who evolved from high parasitemia to low 
parasitemia, however, not all patients who presented reduction in parasitemia, showed improvement in uremic condition, demonstrating that other factors may be associated with this condition, this condition can be more clearly observed in the fact that from the entry to the end of the study, patients with low parasitemia had normal urea mean (less than $50 \mathrm{mg} / \mathrm{dL}$ ) and the highest mean of urea was observed among patients with high pasitemia who, on admission, had $58.5 \mathrm{mg} / \mathrm{dL}$ of mean $\mathrm{d}$ and urea and at the end of the study the only patient in this condition had urea of $37 \mathrm{mg} / \mathrm{dL}$, while meanwhile, patients who had medium parasitemia showed a variation in the mean urea from $49.3 \mathrm{mg} / \mathrm{dL}$ to $79 \mathrm{mg} / \mathrm{dL}$ (Fig.3). Another study carried out at the same hospital found that patients with low parasitemia had mean urea of $76.9 \mathrm{mg} / \mathrm{dL}$, patients with high parasitemia had mean urea of $91.9 \mathrm{mg} / \mathrm{dL}$ and patients with hyper parasitemia had mean urea of $112.9 \mathrm{mg} / \mathrm{dL}$ and it was in this group of patients where the greatest clinical history of infection and treatment of malaria occurred (Calice-Silva et al., 2018). According to WHO (2014), laboratory indicators of poor prognosis reflect the size of the parasitic load (parasite count, parasite development stage, neutrophil pigment), the degree of microvascular obstruction (lactate, bicarbonate) and the extent of organ dysfunction or damage (urea, creatinine, glucose, bilirubin, transaminases, hemoglobin, platelet count) and these aspects had already been described in other studies (Elhassan and Schrier, 2011; Etim et al., 2011).

The majority of patients treated with Artemether were found in the study and it was noticed that these patients presented a great reduction in hyperemia, from 18 on admission to a number of 12 on day 4 of hospitalization, although there was no significant reduction among patients with increased uremia; patients treated with Artesunate showed a slight reduction in patients with hyper uremia at admission from 12 to 10 at the end of the study, without change among patients with increased uremia, however, it was clear that patients treated with Artemether presented mean urea value from admission to the end of the study (less than $50 \mathrm{mg} / \mathrm{dL}$ ) and Artesunate treated patients experienced very high urea averages at entry $(77.8 \mathrm{mg} / \mathrm{dL})$ and the end of the study $(70.4 \mathrm{mg} / \mathrm{dL})$. Among patients treated with Quinine the average urea increased by 1 patient with urea of $14 \mathrm{mg} / \mathrm{dL}$ on admission to 4 patients with a urea average of $71 \mathrm{mg} / \mathrm{dL}$ (Fig.4). These data, differ from other studies carried out in the hospital Josina Machel, the majority of patients with malaria included in the study were treated with quinine medication at 61\% (53/86), mainly patients with low (79\%), high (58\%) and hyper parasitemia $(60 \%)$, the drugs quinine and Artesunate were used mainly in patients with AKI, while Artemether was used mainly in patients without AKI, on the other hand, the combination Quinine and Artemether was used mainly in patients with AKI, while the Quinine and Artesunate combination was used mainly in patients without AKI (Calice-Silva et al., 2018). Blood urea or blood urea nitrogen (BUN) are more prone to confounding factors, such as hydration and the patient's metabolic status (Elhassan and Schrier, 2011; Etim et al., 2011), A prospective multicenter study involving 54 ICUs in 23 countries, the timing of renal replacement therapy (RRT) was stratified into 'early' or 'late' according to the median blood urea concentration at the time the RRT started and also categorized temporarily from admission to the ICU to the beginning ( $<2$ days), delayed (2-5 days) or delayed (>5 days) ${ }^{19}$ (Von Seidlein et al., 2012).

In the study, it was noticed that remained hospitalized had a higher number of cases of hyper uremia on admission (14) and there was a reduction in the number of patients with hyper uremia (10) after 4 days of hospitalization, however, there was an increase in the number of patients with increased uremia (from 20 to 22). There were a greater reduction in discharged patients with hyperemia (from 11 to 9) and those with increased uremia (from 8 to 6 ), while among the deceased patients there was no change. The mean urea among the patients who were discharged from the hospital had a slight reduction (from $51.7 \mathrm{mg} / \mathrm{dL}$ to $44.8 \mathrm{mg} / \mathrm{dL}$, among the patients who remained hospitalized there was also a slight reduction (from $5.5 \mathrm{mg} / \mathrm{dL}$ to $49.1 \mathrm{mg} / \mathrm{dL}$ ) and the interesting thing is that the average urea value among patients who died did not suffer a significant difference since at admission it was $73.6 \mathrm{mg} / \mathrm{dL}$ at admission to $74.1 \mathrm{mg} / \mathrm{dL}$ (Fig.5). One study stated that the reduction in the level of $\mathrm{Na}+$ in patients with malaria, could be associated with losses of sodium in sweat and urine throughout the body, which can serve to compensate for the increased levels of lactase and urea, commonly found in patients with P.falciparum (Etim et al., 2011; Von Seidlein et al., 2012). In severe malaria, increased blood urea on admission may also have a prognostic significance $^{15}$, in the study conducted at the same hospital, three patients $(3.5 \%)$ received hem dialysis and eight $(9.3 \%)$ died during the four days of follow-up, among the patients who died, $5 / 8(62.5 \%)$ had KD, compared to $3 / 8$ $(37.5 \%)$ without $\mathrm{KD}(\mathrm{p}=0.047)^{10}$. A measure of blood urea $>20 \mathrm{mM}$ (above $\left.50 \mathrm{mg} / \mathrm{dL}\right)$ in children or adults with severe malaria is a prognosis that identifies a high-risk group with mortality above $30 \%$ (Hanson et al., 2013).

\section{Conclusion:-}

This study reinforce the piece of evidence that the uremia undergoes alterations before the most severe malaria condition sets in, and it may be one of the reasons that lead the patient to seek help at the hospital and the uremic condition of these patients pass through few changes during medical treatment. The social factors such as age, place 
of residence, and work condition may have caused slight changes in the uremic condition of patients but it does not have a very significant effect on the mean urea values during hospitalization. However, clinical factors such as degree of parasitemia and pharmacological treatment directly affect the uremic condition of patients with malaria and that uremic condition can be a predictor of mortality. Although the uremic condition is always associated with acute kidney injury, it can be an indicator of other clinical conditions, and therefore it is necessary to pay extra attention to patients with malaria in order to provide quality medical and medication assistance in order to reduce malaria complications.

\section{Limitation of the study:}

The study was limited by the fact that there was no relationship between urea and creatinine, and it was intentional to not associate urea solely and exclusively with acute kidney injury that is diagnosed specifically by creatinine. The results found in this study show a picture of this issue in the populations studied in the specific time point, and can't be extrapolated to all Luanda or Angolan people. The other limitation is that the fact that the number of patients, although reasonable, was not carried out using inferential statistics, but rather descriptive statistics so that each situation could be assessed independently and so that the conclusions related to that study can be seen as aspects that differ from person to person.

\section{Acknowledgment:-}

The authors would like to thank the patients for their participation and the international Society Nephrology (ISN) for funding the study (Research and Prevention Program and Saving Young Lives). Moreover, to thank the management and the workers from Josina Machel Hospital for institutional support.

\section{Bibliographic References:-}

1. Afrifa J, Essien-Baidoo S, Gyau AB, Ephraim RKD. (2017) Evaluation of Renal Function in Pregnant Women with Malaria: A Case-Control Study in a Mesoendemic Area. Obstetrics and Gynecology International. https://doi.org/10.1155/2017/6030943.

2. Akanbi, OM (2015) The influence of malaria infection on kidney and liver function in children in Akoko area of Ondo state, Nigeria. Journal of Parasitology and Vector Biology. Vol. 7(8), pp. 163-168. DOI: 10.5897/JPVB2015.0200

3. Angola. Ministry of Health. National Malaria Control Program. 05/11/2020. [Cited 2020 June 25]. Available from: https://pt.euronews.com/2020/05/11/mais-de-2-500-mortes-por-malaria-so-este-ano-em-angola

4. Aregawi S, Li L, Miraglia CM. (2017). Malaria rapid diagnostic test and Giemsa - stained peripheral blood smear discrepancies in the diagnosis of Plasmodium ovale infection in New England. American Society for Clinical Laboratory Science. 30 (2) 75-83; DOI: 10.29074/ascls.30.2.75

5. Calice-Silva V, Sacomboio E, Raimann JG et al. (2018) Diagnostic performance of salivary urea nitrogen dipstick to detect and monitor acute kidney disease in patients with malaria. Malar J 17,477 https://doi.org/10.1186/s12936-018-2627-4.

6. Elhassan E \& Schrier R (2011). Acute Kidney Injury. In Textbook of Critical Care Medicine, (eds Moore F, Vincent J-L, Abraham E, Kochanek P \& Fink M) Elsevier, Philadelphia.

7. Etim OE, Ekaidem IS, Akpan EJ, Usoh IF, Akpan HD (2011). Changes in electrolyte levels in uncomplicated Plasmodium falciparum malaria: the effects of quinine therapy. Cont. J. Pharmacol. Toxicol. Res. 4:5- 10.

8. Gramaglia I, Velez J, Chang Y-S, Caparros-Wanderley W, Combes V, Grau G, et al. (2019) Citrulline protects mice from experimental cerebral malaria by ameliorating hypoargininemia, urea cycle changes and vascular leak. PLoS ONE 14(3): e0213428. https://doi.org/10.1371/journal.pone.0213428.

9. Hanson JP, Lam SW, Mohanty S, et al. (2013) Fluid resuscitation of adults with severe falciparum malaria: effects on Acid- base status, renal function, and extravascular lung water. Critical Care Medicine 41, 972-981.

10. Meier A, Erler H and Beitz E. (2018). Targeting Channels and Transporters in Protozoan Parasite Infections. Front. Chem. 6:88. doi: 10.3389/fchem.2018.00088.

11. Padhi RK, Mishra S (2012). Incidence of renal involvement in malaria in children of Odisha. ISRN Nephrol. $\mathrm{p}$ 4.

12. Sacomboio ENM, Sebastião CS, Tchivango AT, Pecoits-Filho R, Calice-Silva V. (2020) Does parasitemia level increase the risk of acute kidney injury in patients with malaria? Results from an observational study in Angola. Scientific African. Volume 7, March. doi:10.1016/j.sciaf.2019.e00232. 
13. Von Seidlein L, Olaosebikan R, Hendriksen IC, et al. (2012) Predicting the clinical outcome of severe falciparum malaria in African children: findings from a large randomized trial. Clinical Infectious Diseases 54, 1080-1090.

14. Von Seidlein L, Olaosebikan R, Hendriksen IC, et al. (2012) Predicting the clinical outcome of severe falciparum malaria in African children: findings from a large randomized trial. Clinical Infectious Diseases 54, 1080-1090.

15. White NJ, Pukrittayakamee S, Hien TT, Faiz MA, Mokuolu OA, Dondorp AM. Malaria. Lancet 2014; 383:72335 .

16. WHO. Tropical Medicine and International Health. (2014) WHO. Tropical Medicine and International Health is published by John Wiley \& Sons., 19 (Suppl. 1), 7-131. doi:10.1111/tmi.12313.

17. WHO. WHO warns malaria deaths in Africa could double amid pandemic: Top health officials urge countries to ensure essential malaria prevention work continues during corona virus pandemic. 2020 April 23. [Cited 2020 June 25]. Available from: https://www.aljazeera.com/news/2020/04/warns-malaria-deaths-africa-doublepandemic-200423182645239.html.

18. Yeo TW, Lampah DA, Kenangalem E, Tjitra E, Weinberg JB, Granger DL, et al. (2014) Decreased endothelial nitric oxide bioavailability, impaired microvascular function, and increased tissue oxygen consumption in children with falciparum malaria. J Infect Dis.;210(10):1627-32. pmid:24879801.

19. Zaki HY, Abdalla BE, Hayder B (2013). Biochemical Profiles of Children with Severe Plasmodium falciparum malaria in central Sudan: a casecontrol study. Al Neelain Med. J. 3: 15-23.

20. Zanner MA, Galey WR, Scaletti JV, Brahm J, Jagt DLV. (2019) Immunology and Microbiology; Biochemistry, Genetics and Molecular Biology. Molecular and Biochemical Parasitology.. PMID2194124. DOI:10.1016/0166-6851(90)90048-q. 